\title{
Commentary Pain may be inevitable; inadequate management is not
} Yoanna Skrobik

Hôpital Maisonneuve Rosemont, 5415 boulevard de l'Assomption, Montreal, Québec, Canada H1T 2M4

Corresponding author: Yoanna Skrobik, skrobik@sympatico.ca

Published: 29 April 2008

This article is online at http://ccforum.com/content/12/2/142

(c) 2008 BioMed Central Ltd

See related research by Ahlers et al., http://ccforum.com/content/12/1/R15

Critical Care 2008, 12:142 (doi:10.1186/cc6865)

\begin{abstract}
Assessing and managing pain in the critically ill patient is challenging. Reproducible and clinically applicable pain measurement scales have yet to be validated and ubiquitously applied in the intensive care unit setting. Critical care clinicians, both physicians and nurses, should thoughtfully monitor their patient's pain level, periodically reassess their practice and critically evaluate the efficacy of pharmacological and nonpharmacological analgesic interventions.
\end{abstract}

Pain assessment is challenging. In the critical care setting, two factors interfere with such appraisals: the preoccupation with the disease process and the urgency of the necessary interventions on the part of the busy caregiver, on one hand; and the presumed inability of the patient to communicate, on the other. The recent study by Ahlers and colleagues is important because it demonstrates the latter may be largely untrue. The authors show that pain assessment can be performed in the majority of intensive care unit (ICU) patients even if very ill - and that the scales available for its evaluation are useful [1].

All patients deserve to be pain free. ICU survivors rate painlessness as one of the most important [2], yet unfulfilled [3], parameters during their ICU stay. Pain assessment is performed according to acceptable standards in probably $<50 \%$ of ICU patients, even in the context of observational studies [4] where caregivers know their pain evaluations are being monitored. Nurses and physicians fail to enquire about pain, presume painlessness, or judge the pain level - or its absence - without validating its degree with the patient. Adult patients describe maximal discomfort while being moved (for example, turned in bed) or suctioned; discomfort is greatest in adolescents around wound care and dressing changes [5]. Premedication prior to mobilization or other daily tasks is not part of routine critical care practice even if its use has been shown to be beneficial. Pain assessments are usually performed at rest; pain upon mobilization or coughing is not verified. In addition, whether sedative drugs or ICU delirium cloud the ability of the patient to convey the presence or the degree of pain is unknown.

There is huge interindividual variability in both the pain threshold and the sensitivity to various analgesic drugs in postoperative patients [6]. Such variability is at least as great in the ICU. This variability makes assessment necessary, as without assessment the individual variability in pain perception and response to analgesia cannot be evaluated. Moreover, especially in the ICU, pain can be complicated by psychomotor agitation or delirium. The clinician must therefore decide whether, in an individual patient, the issue is pain or frightening hallucinations. Simultaneous evaluations of pain, first and foremost, then of sedation, to avoid excessive sedative administration, and finally of delirium, to differentiate delirium symptoms that may be confounders for pain and insufficient sedation, should be routine in ICU patients. Administering the wrong pharmacologic intervention for any of these symptoms, especially an intervention that can lead to iatrogenic coma, can lead to harm [7] and may not resolve the underlying problem. Gauging pain and differentiating pain from confounding symptoms are thus both important.

Critical care nurses and physicians live with a paradox regarding pain. They purport to have a strong commitment to pain relief, but the documented underestimation and undertreatment of their patients' pain has been deplored for over 20 years [8]. Few have asked why, but staff workload [9] and organizational culture issues [10] are sometimes blamed. After pain assessment, evaluation of the effectiveness and titration of analgesics is hailed as the desirable standard in most recommendations. How can adequate patient care be assured? Implementation of protocols, unfortunately, is no panacea. Physicians and nurses disagree as to the level of pain as well as to efficacy of analgesic drugs [11]. Moreover,

$\mathrm{ICU}=$ intensive care unit. 
an overall observance of one center's multidisciplinary analgesia and sedation protocol was documented to be $23 \%$, with all participants - nurses and physicians - significantly over-rating their performance as to protocol adherence [12].

Even if analgesia was monitored adequately and medications administered according to need, the ideal approach to management of pain in the ICU is unclear. Opiates are used routinely [13], but their usefulness as analgesics for different ICU types of pain, their effects with longitudinal use, and their interactions with other drugs are poorly described [14]. We assume an administered drug dose translates into proportional changes in blood and central nervous system drug levels, and in expected clinical effect. Several metabolic pathways, however (affecting fentanyl, for instance), are affected by inflammation, postoperative status and genetic variants. Aside from opiates, although acetaminophen [15] and nonsteroidal anti-inflammatory drugs reduce opiate requirements in other hospitalized populations and potentially improve pain management, their potential side effects in the critically ill patient are not well described [16] and may well be significant. Potentiating analgesic effects with sedatives or other pharmacologic agents remains unexplored. Nonpharmacologic interventions, such as music and relaxation techniques, have been shown to be effective in oncology and in postoperative patients. Prospective studies with these minimally invasive approaches in the vulnerable ICU population are lacking.

Although multiple barriers exist that mitigate against the perfect management of pain in the ICU, the first step is to measure the pain and to measure the response to initial therapy. Without this measurement, all of the downstream measures are probably in vain. Our challenge as a critical care community is to better serve our patients and their outcomes by evaluating and managing pain better. The recent article by Ahlers and colleagues is a step in that direction.

\section{Competing interests}

The author declares that they have no competing interests.

\section{References}

1. Ahlers SJ, van Gulik L, van der Veen AM, van Dongen HP, Bruins P, Belitser SV, de Boer A, Tibboel D, Knibbe CA: Comparison of different pain scoring systems in critically ill patients in a general ICU. Crit Care 2008, 12:R15.

2. Turner JS, Briggs SJ, Springhorn HE, Potgieter PD: Patients' recollection of intensive care unit experience. Crit Care Med 1990; 18:966-968.

3. Desbiens NA, Wu AW, Broste SK, Wenger NS, Connors AF Jr, Lynn J, Yasui Y, Phillips RS, Fulkerson W: Pain and satisfaction with pain control in seriously ill hospitalized adults: findings from the SUPPORT research investigations. For the SUPPORT investigators. Study to Understand Prognoses and Preferences for Outcomes and Risks of Treatment. Crit Care Med 1996, 24:1953-1961.

4. Devlin JW, Marquis F, Riker RR, Robbins T, Garpestad E, Fong JJ, Didomenico D, Skrobik Y: Combined didactic and scenariobased education improves the ability of intensive care unit staff to recognize delirium at the bedside. Crit Care 2008, 12: R19.
5. Puntillo KA, White C, Morris AB, Perdue ST, Stanik-Hutt J, Thompson CL, Wild LR: Patients' perceptions and responses to procedural pain: results from Thunder Project II. Am J Crit Care 2001, 10:238-251.

6. Fagerlund $\mathrm{TH}$, Braaten $\mathrm{O}$ : No pain relief from codeine ...? An introduction to pharmacogenomics. Acta Anaesthesiol Scand 2001, 45:140-149.

7. Ouimet S, Kavanagh BP, Gottfried SB, Skrobik Y: Incidence, risk factors and consequences of ICU delirium. Intensive Care Med 2007, 33:66-73.

8. Hamill-Ruth RJ, Marohn ML: Evaluation of pain in the critically ill patient. Crit Care Clin 1999, 15:35-54, v-vi.

9. Park G, Coursin D, Ely EW, England M, Fraser GL, Mantz J, McKinley S, Ramsay M, Scholz J, Singer M, Sladen R, Vender JS, Wild L, Bair N, Bobek MB, Hoffman-Hogg L, Mion LC, Slomka J, Arroliga AC: Commentary. Balancing sedation and analgesia in the critically ill. Crit Care Clin 2001, 17:1015-1027.

10. Glynn G, Ahern M: Determinants of critical care nurses' pain management behaviour [review]. Aust Crit Care 2000, 13:144151.

11. Slomka J, Hoffman-Hogg L, Mion LC, Bair N, Bobek MB, Arroliga AC: Influence of clinicians' values and perceptions on use of clinical practice guidelines for sedation and neuromuscular blockade in patients receiving mechanical ventilation. $\mathrm{Am} J$ Crit Care 2000, 9:412-418.

12. Bair N, Bobek MB, Hoffman-Hogg L, Mion LC, Slomka J, Arroliga $\mathrm{AC}$ : Introduction of sedative, analgesic, and neuromuscular blocking agent guidelines in a medical intensive care unit: physician and nurse adherence. Crit Care Med 2000, 28:707713.

13. Mehta S, Burry L, Fischer S, Martinez-Motta JC, Hallett D, Bowman D, Wong C, Meade MO, Stewart TE, Cook DJ, Canadian Critical Care Trials Group: Canadian survey of the use of sedatives, analgesics, and neuromuscular blocking agents in critically ill patients. Crit Care Med 2006, 34:374-380.

14. Haas CE, Forrest A: Pharmacokinetic and pharmacodynamic research in the intensive care unit: an unmet need. Crit Care Med 2006, 34:1831-1833.

15. Peduta VA, Ballabio M, Sefanini S: Efficacy of propacetamol in the treatment of postoperative pain: morphine sparing effect in orthopedic surgery. Italian Collaborative Group on Propacetamol. Acta Anaesthesiol Scand 1998, 42:293-298.

16. Riker RR, Fraser GL: Adverse events associated with sedatives, analgesics, and other drugs that provide patient comfort in the intensive care unit. Pharmacotherapy 2005, 25(5 Pt 2): $8 \mathrm{~S}-18 \mathrm{~S}$. 